\title{
Cobertura nitrogenada em diferentes estádios fenológicos do feijoeiro comum altera produtividade e qualidade de grãos
}

\author{
Gabriel Pereira NOGUEIRA ${ }^{1}$, Mateus Sebastião Gonçalves da SILVA ${ }^{1}$, Fábio Tiraboschi LEAL ${ }^{1 *}$, \\ Rogério FARINELLI ${ }^{1}$, Fábio Luiz Checchio MINGOTTE ${ }^{1}$, Leandro Borges LEMOS ${ }^{1}$
}

\author{
${ }^{1}$ Departamento de Produção Vegetal, Faculdade de Ciências Agrárias e Veterinárias, Universidade Estadual Paulista, \\ Jaboticabal, SP, Brasil. \\ *E-mail: lealft@bol.com.br
}

Recebido em maio/2018; Aceito em julho/2019.

\begin{abstract}
RESUMO: A necessidade de conhecer a marcha de absorção do nitrogênio (N) pelo feijoeiro é importante para compreender os desempenhos produtivo e qualitativo dessa cultura. O objetivo deste estudo foi avaliar a influência da cobertura nitrogenada em função de diferentes estádios fenológicos no desempenho morfoagronômico e produtivo e nas características tecnológicas dos grãos do feijoeiro em sistema de plantio convencional. Utilizou-se o delineamento de blocos casualizados, com quatro repetições. Os tratamentos foram constituídos por doze combinações de fornecimento de $\mathrm{N}(\mathrm{FN})$ em cobertura (dose total $=90 \mathrm{~kg} \mathrm{ha}^{-1}$ de N) aplicadas nos estádios fenológicos $\mathrm{V}_{3}, \mathrm{~V}_{4}$ e $\mathrm{R}_{5}\left(\mathrm{~V}_{3}+\mathrm{V}_{4}+\mathrm{R}_{5}\right)$ do feijoeiro de inverno irrigado: 00+00+00; $30+30+30 ; 30+60+00 ; \quad 30+00+60 ; \quad 60+30+00 ; \quad 00+60+30 ; 45+45+00 ; 00+45+45 ; 45+00+45 ; \quad 90+00+00 ;$ $00+90+00$; e $00+00+90$. A fonte de $\mathrm{N}$ utilizada foi ureia convencional. Os FN $30+00+60,00+45+45$ e $45+00+45$ incrementam a produtividade de grãos e a eficiência agronômica em relação à ausência de $\mathrm{N}$ e à aplicação de dose única no estádio fenológico $\mathrm{V}_{4}$. do feijoeiro comum. As maiores produtividades de proteína bruta e o menor tempo para cozimento foram proporcionadas pelos FN $00+45+45,45+00+45,90+00+00,00+90+00$ e $00+00+90$.

Palavras-chave: Phaseolus vulgaris; parcelamento do N; eficiência agronômica; tecnologia dos grãos.
\end{abstract}

\section{Nitrogen topdressing at different phenological stages on common bean changes grain yield and quality}

\begin{abstract}
The need to know the nitrogen uptake $(\mathrm{N})$ by common bean is important to understand the productive and qualitative performance of this crop. The objective of this study was to evaluate the influence of nitrogen topdressing as a function of different phenological stages on the morphometric and productive performance, and on the technological characteristics of the bean grains grown under conventional soil preparation. A randomized block design with four replications was used. The treatments were constituted by twelve topdressing $\mathrm{N}$ supply combinations (NS) (total dose $=90 \mathrm{~kg} \mathrm{ha}^{-1} \mathrm{~N}$ ) applied in the phenological stages $\mathrm{V}_{3}, \mathrm{~V}_{4}$ and $\mathrm{R}_{5}\left(\mathrm{~V}_{3}+\mathrm{V}_{4}+\mathrm{R}_{5}\right)$ of irrigated winter bean: $00+00+00 ; 30+30+30 ; 30+60+00 ; 30+00+60 ; 60+30+00$; $00+60+30 ; 45+45+00 ; 00+45+45 ; 45+00+45 ; 90+00+00 ; 00+90+00$; and $00+00+90$. The source of $\mathrm{N}$ used was conventional urea. NS $30+00+60,00+45+45$ and $45+00+45$ increase grain yield and agronomic efficiency in relation to the absence of $\mathrm{N}$ and single dose application at $\mathrm{V}_{4}$ phenological stage of common bean. The highest crude protein yields and the shortest cooking time were provided by FN $00+45+45,45+00+45,90+00+00$, $00+90+00$ and $00+00+90$.
\end{abstract}

Keywords: Phaseolus vulgaris; N splitting; agronomic efficiency; grains technology.

\section{INTRODUÇÃO}

Dentre os nutrientes, o nitrogênio $(\mathrm{N})$ é o mais extraído pela cultura do feijoeiro comum (Phaseolus vulgaris L.) exigindo em média de $36,5 \mathrm{~kg}$ de N para cada $1000 \mathrm{~kg}$ de grãos produzidas (FAGERIA et al., 2015). Embora seja uma legumisosa capaz de realizar fixação biológica de $\mathrm{N}(\mathrm{FBN})$ por meio de associações com bactérias do gênero Rhizobium, ainda é imprescindível a aplicação de $\mathrm{N}$ via adubação mineral na semeadura e em cobertura (KANEKO et al., 2010). Esse fato se deve principalmente aos seguintes fatores: insuficiência da FBN (KANEKO et al., 2010; FIGUEIREDO et al., 2016) e elevada exportação do nutriente para os grãos $(50 \%$ do $\mathrm{N}$ absorvido é exportado para os grãos) (PEREZ et al., 2013). Ademais, o feijoeiro pode apresentar maior necessidade de $\mathrm{N}$ mineral disponível nos estádios iniciais (CRUSCIOL et al.,
2007), devido seu ciclo curto, raízes pouco profundas, e que $70 \%$ das necessidades nutricionais da cultura é absorvido na fase vegetativa (SORATTO et al., 2013; SOARES et al., 2015). Salienta-se também que a adubação nitrogenada representa alto custo e reduzida eficiência de aproveitamento pelas plantas. Dessa forma, são necessárias estratégias que visem aumentar a eficiência de uso desse nutriente, permitindo a sustentabilidade dos sistemas agrícolas.

Nesse sentido, o fornecimento de $\mathrm{N}$ em cobertura em diferentes estádios fenológicos do feijoeiro pode ser uma alternativa interessante, pois sincronizaria a marcha de absorção aos processos de imobilização e mineralização desse nutriente no solo (SORATTO et al., 2013; FLÔRES et al., 2017). Assim, pesquisas tem proposto a antecipação da aplicação do $\mathrm{N}$ como alternativa de manejo, seja na pré- 
semeadura (na cultura anterior), na semeadura ou no próprio feijoeiro em cobertura (NASCENTE et al., 2012; NASCENTE et al., 2017a; SORATTO et al., 2013; FLÔRES et al., 2017), principalmente no sistema de plantio direto, havendo poucas informações para o sistema de preparo convencional do solo. No entanto, deve-se ter precauções quanto a antecipação para a pré-semeadura e semeadura devido aos riscos de maior lixiviação e salinização das sementes (CERETTA et al., 2002) e, em doses elevadas de $\mathrm{N}$ na semeadura, ocasionar prejuízos a FBN. Atualmente, as recomendações de adubação nitrogenada em cobertura para o feijoeiro, na sua maior parte, sugerem ainda a aplicação do $\mathrm{N}$ em dose única na presença do terceiro trifólio $\left(\mathrm{V}_{4}\right)$ (AMBROSANO et al., 1997).

Além disso, a maioria dos trabalhos avalia apenas a produtividade de grãos e a eficiência agronômica. Esse fato evidencia a necessidade de pesquisas que avaliem a influência dos tratos culturais, principalmente da adubação nitrogenada, nas qualidades nutricionais e tecnológicas dos grãos do feijoeiro, conforme reportado por Farinelli; Lemos (2010a), Mingotte et al. (2013), Amaral al. (2016) e Flôres et al. (2017). Destaca-se que, o $\mathrm{N}$ após ser absorvido pelas raízes, é combinado a compostos orgânicos formando aminoácidos, que resultam em proteínas acumuladas nos grãos (PEREZ et al., 2013; AMARAL et al., 2016). Dessa forma, os modos de fornecimento de $\mathrm{N}$ em cobertura podem também alterar características nutricionais e tecnológicas dos grãos como teor de proteína, tempo de cozimento, tempo de máxima hidratação e relação de hidratação.

O objetivo deste estudo foi avaliar a influência da cobertura nitrogenada, em função de diferentes estádios fenológicos no desempenho morfoagronômico, produtivo, e nas características tecnológicas dos grãos do feijoeiro em sistema de plantio convencional.

\section{MATERIAL E MÉTODOS}

\subsection{Localização e histórico da área experimental}

O experimento foi conduzido durante o ano agrícola de 2008/09 na Fazenda Santa Bárbara, em Guaíra, no Norte do Estado de São Paulo, de em altitude média de 520 metros acima do nível do mar, com clima Aw (tropical úmido com estação chuvosa no verão e seca de inverno), em Latossolo Vermelho distrófico (EMBRAPA, 2013) de textura argilosa e relevo plano, cultivado com soja na safra anterior (verão 2007/08) no sistema de preparo convencional do solo sendo manejada com grade intermediária e niveladora, anteriormente a semeadura do feijoeiro. Antes da instalação do experimento, procedeu-se à retirada de amostras de solo para fins de análise dos atributos químicos na camada $0-20 \mathrm{~cm}$. Os resultados da análise foram: $\mathrm{pH}\left(\mathrm{CaCl}_{2}\right) 5,4$; matéria orgânica $=36 \mathrm{~g} \mathrm{~kg}^{-1} ; \mathrm{P}$ (resina) $=49 \mathrm{mg} \mathrm{dm}{ }^{-3} ; \mathrm{H}+\mathrm{Al}=31 \mathrm{mmol}_{\mathrm{c}} \mathrm{dm}^{-3}$; $\mathrm{K}=2 \mathrm{mmol}_{\mathrm{c}} \mathrm{dm}^{-3} ; \mathrm{Ca}=28 \mathrm{mmol}_{\mathrm{c}} \mathrm{dm}^{-3}, \mathrm{Mg}=10 \mathrm{mmol}_{\mathrm{c}} \mathrm{dm}$ 3; $\mathrm{CTC}=71 \mathrm{mmol}_{\mathrm{c}} \mathrm{dm}^{-3}$ e V $=57 \%$.

\subsection{Delineamento experimental e tratamentos}

O delineamento experimental foi o de blocos casualizados, com quatro repetições. Os tratamentos foram constituídos por doze combinações de fornecimento de $\mathrm{N}(\mathrm{FN})$ em cobertura $\left(\right.$ dose total $=90 \mathrm{~kg} \mathrm{ha}^{-1}$ de $\left.\mathrm{N}\right)$ aplicadas nos estádios fenológicos $\mathrm{V}_{3}$ (formação do primeiro trifólio), $\mathrm{V}_{4}$ (presença da terceira folha trifoliolada) e $\mathrm{R}_{5}$ (pré-florescimento) $\left(\mathrm{V}_{3}+\mathrm{V}_{4}+\mathrm{R}_{5}\right)$ do feijoeiro de inverno irrigado: $00+00+00$ (controle); 30+30+30; 30+60+00; 30+00+60; 60+30+00; $00+60+30 ; 45+45+00 ; 00+45+45 ; 45+00+45 ; 90+00+00$;
00+90+00; e 00+00+90. A dose de $90 \mathrm{~kg} \mathrm{ha}^{-1}$ foi estabelecida com base na recomendação para o Estado de São Paulo para solo com alta probabilidade de resposta à aplicação de $\mathrm{N}$ e com expectativa de produtividade de grãos entre 3,5-4,5 t ha ${ }^{-1}$ (AMBROSANO et al., 1997). Como fonte de $\mathrm{N}$ foi utilizada a ureia convencional em filete contínuo a $10 \mathrm{~cm}$ da linha da cultura, com incorporação via irrigação aplicando-se $15 \mathrm{~mm}$ de lâmina d'água. Cada parcela foi composta por cinco linhas de feijão espaçadas a 0,47 metros $(\mathrm{m})$, com cinco metros de comprimento, considerando-se como área útil as três linhas centrais, desprezando-se $0,5 \mathrm{~m}$ de cada extremidade.

\subsection{Semeadura e condução do feijoeiro comum}

A cultivar de feijoeiro comum "Pérola" foi semeada mecanicamente em 12/05/2008 (safra de inverno), distribuindo-se 12 sementes por metro, equivalente a 2,6 plantas por $\mathrm{m}^{2}$. As sementes foram previamente tratadas com os produtos carbendazim + tiram (45 g e $105 \mathrm{~g}$ de ingrediente ativo por $100 \mathrm{~kg}$ de sementes, respectivamente) e tiametoxam (140 g do i.a. por $100 \mathrm{~kg}$ de sementes). As sementes não foram inoculadas com bactérias do gênero Rhizobium. A adubação de semeadura foi de $330 \mathrm{~kg} \mathrm{ha}^{-1}$ do formulado 8-28-16. A irrigação da área foi realizada com sistema de aspersão do tipo pivô-central, com turno de rega de 3 dias, com aplicação de 10 mm de lâmina d'água realizada por volta das 10 horas da manhã. $\mathrm{O}$ controle de plantas daninhas de pós-emergência foi realizado por meio de herbicidas seletivos fomesafen $(250 \mathrm{~g}$ $\mathrm{ha}^{-1}$ do i.a) e fluazifop-p-butil (125 $\mathrm{g} \mathrm{ha}^{-1}$ do i.a.). Para o controle fitossanitário, realizou-se a aplicação de thiamethoxan $\left(14,1 \mathrm{~g} \mathrm{ha}^{-1}\right.$ do i.a.+ lambda-cialotrina $(10,6 \mathrm{~g}$ ha $^{-1}$ do i.a,), aos 35 DAE (dias após a emergência); abamectina (9 $\mathrm{g} \mathrm{ha}^{-1}$ do i.a.), lufenuron (7,5 $\mathrm{g} \mathrm{ha}^{-1}$ do i.a.), azoxistrobina (20 $\mathrm{g} \mathrm{ha}^{-1}$ do i.a.) + ciproconazol (8 $\mathrm{g} \mathrm{ha}^{-1}$ do i.a.), aos $49 \mathrm{DAE}$ e e tebuconazol (200 $\mathrm{g} \mathrm{ha}^{-1}$ do i.a.) aos 62 DAE.

2.4. Avaliações morfoagronômicas, produtivas e qualitativas do feijoeiro comum

Por ocasião do florescimento pleno do feijoeiro $\left(\mathrm{R}_{6}\right)$ foram coletados trifólios do terço médio em 30 plantas por parcela para determinação do teor de nitrogênio total foliar por meio de digestão com ácido sulfúrico. Após a maturidade fisiológica $\left(\mathrm{R}_{9}\right)$, em uma das linhas da área útil de cada parcela, foram coletadas dez plantas consecutivas para a determinação do número de vagens por planta, número de grãos por vagem e massa de 100 grãos. A produtividade de grãos foi obtida após arranquio manual e trilha mecanizada das plantas presentes nas três linhas centrais de cada parcela, com determinação do grau de umidade dos grãos, padronizando-se para $0,13 \mathrm{~kg} \mathrm{~kg}^{-1} \mathrm{em}$ base úmida.

A eficiência agronômica (EA) foi calculada utilizando-se a fórmula $\mathrm{EA}=(\mathrm{PGcf}-\mathrm{PGsf}) /(\mathrm{QNa})$, expressa em $\mathrm{kg} \mathrm{kg}^{-1}$, em que PGcf é a produção de grãos com fertilizante nitrogenado; PGsf é a produção de grãos sem fertilizante nitrogenado; e QNa é a quantidade de $\mathrm{N}$ aplicado em $\mathrm{kg}$.

Após a colheita e determinação da produtividade dos grãos do feijoeiro, amostras de grãos de cada subparcela foram acondicionadas em sacos de papel e armazenadas por 60 dias em câmara seca a temperatura de $25^{\circ} \mathrm{C}$ e umidade relativa de $40 \%$. Após esse período, as amostras foram submetidas a avaliações das características tecnológicas. $\mathrm{O}$ teor de proteína bruta foi determinado pela fórmula $\mathrm{PB}=\mathrm{N}$ total $\mathrm{x} 6,25$, em que o $\mathrm{N}$ total é o teor de nitrogênio nos grãos, obtido na digestão sulfúrica e 6,25 é o fator de conversão para proteína 
indicado pela Association of Official Analytical Chemists AOAC (1995). Os dados referentes ao teor de proteína bruta nos grãos foram multiplicados pela produtividade de grãos, obtendo-se a produtividade de proteína bruta por área.

O tempo para cozimento, expresso em minutos, foi determinado com o auxílio do cozedor de Mattson, que consta basicamente de 25 estiletes verticais, cada um com peso de 90 gramas, terminados em ponta de 1/16" de diâmetro. A ponta fica apoiada no grão de feijão durante o cozimento e quando o grão encontra-se cozido a ponta penetra-o deslocando o estilete. $\mathrm{O}$ tempo final para cozimento da amostra foi obtido quando $50 \%+1$, ou seja, com 14 estiletes deslocados. Para essa determinação os grãos foram hidratados anteriormente em água destilada durante um período de 12 horas. Durante a condução do teste a temperatura da água foi mantida a $96^{\circ} \mathrm{C}$. De posse dos dados, adotou-se a escala de Proctor; Watts (1987) para verificar o nível de resistência dos grãos ao cozimento, sendo classificado como: muito suscetível $(<16$ minutos); suscetibilidade média (16 a 20 minutos); resistência normal (21 a 28 minutos); resistência média (29 a 32 minutos); resistente (33 a 36 minutos) e muito resistente ( $>36$ minutos).

\subsection{Análise estatística dos resultados}

Os dados foram submetidos à análise de variância pelo teste $\mathrm{F}(\mathrm{p}<0,05)$ e as médias foram agrupadas por meio do teste Scott e Knott $(\mathrm{p}<0,05)$.

\section{RESULTADOS}

Os FN não diferiram significativamente entre si quanto ao teor total de $\mathrm{N}$ foliar, com valor médio de $56,25 \mathrm{~g} \mathrm{~kg}^{-1}$. Porém, o menor valor observado para o teor de $\mathrm{N}$ na folha diagnóstica foi quando não realizada a adubação nitrogenada em cobertura (47 $\left.\mathrm{g} \mathrm{kg}^{-1}\right)$ (Tabela 1).

Em relação aos componentes de produção, produtividade e eficiência agronômica, o número de vagens por planta foi incrementado pela aplicação de N. Dentre os parcelamentos, o $00+60+30$ apresentou o menor número de vagens por planta. $\mathrm{O}$ número de grãos por vagem não foi influenciado pela adubação nitrogenada, com média de 5,60 grãos por vagem. A massa de 100 grãos não foi alterada significativamente pela aplicação do $\mathrm{N}$ em cobertura e pelos parcelamentos em diferentes estádios fenológicos da cultura.

Os tratamentos $30+00+60, \quad 00+45+45$ e $45+00+45$ proporcionaram as maiores produtividades de grãos e eficiência agronômica com valores de $3.970,4.088$ e $3.835 \mathrm{~kg}$ $\mathrm{ha}^{-1}$, e índices de eficiência de 12,59; 11,27 e $9,78 \mathrm{~kg} \mathrm{~kg}^{-1}$, respectivamente. Esses FN foram superiores aos tratamentos com aplicação de $90 \mathrm{~kg} \mathrm{ha}^{-1}$ de $\mathrm{N}$ em dose única $(90+00+00$; $00+90+00 ; 00+00+90)$, que não diferiram da ausência de $\mathrm{N}$ (Tabela 1)

Tabela 1. Teor de nitrogênio total foliar, número de vagens por planta, número de grãos por vagem, massa de 100 grãos, produtividade de grãos e eficiência agronômica do feijoeiro em função das combinações de fornecimento de nitrogênio em cobertura no sistema de preparo convencional do solo, Guaira-SP, $2008^{(1)}$.

Table 1. Total leaf nitrogen content, number of pods per plant, number of grains per pod, mass of 100 grains, grain yield, and agronomic efficiency of common bean as a function of topdressing nitrogen supply combinations in the conventional tillage system, Guaira- SP, $2008^{(1)}$.

\begin{tabular}{|c|c|c|c|c|c|c|}
\hline Tratamentos & $\begin{array}{l}\text { Teor de } \mathrm{N} \\
\text { total foliar } \\
--\mathrm{g} \mathrm{kg}^{-1}--\end{array}$ & $\begin{array}{c}\text { Vagens } \\
\text { por planta }\end{array}$ & $\begin{array}{c}\text { Grãos } \\
\text { por vagem }\end{array}$ & $\begin{array}{l}\text { Massa de } \\
100 \text { grãos } \\
---- \text { g ---- }\end{array}$ & $\begin{array}{l}\text { Produtividade } \\
\text { de grãos } \\
\text {--- } \mathrm{kg} \mathrm{ha}^{-1} \text {--- }\end{array}$ & $\begin{array}{c}\text { Eficiência } \\
\text { Agronômica } \\
--\mathrm{kg} \mathrm{kg}^{-1}--\end{array}$ \\
\hline $\begin{array}{l}\text { Fornecimentos de } \\
00+00+00\end{array}$ & 47,33 & $13,50 \mathrm{~b}$ & 6,01 & 25,32 & $2.955,46 \mathrm{~b}$ & - \\
\hline $30+30+30$ & 55,33 & $18,15 \mathrm{a}$ & 5,74 & 26,03 & $3.482,86 \mathrm{~b}$ & $5,86 \mathrm{~b}$ \\
\hline $30+60+00$ & 57,00 & $18,63 \mathrm{a}$ & 5,32 & 25,93 & $3.448,22 \mathrm{~b}$ & $5,47 \mathrm{~b}$ \\
\hline $30+00+60$ & 54,00 & $18,70 \mathrm{a}$ & 5,39 & 26,99 & $3.970,11 \mathrm{a}$ & $11,27 \mathrm{a}$ \\
\hline $60+30+00$ & 57,67 & $18,10 \mathrm{a}$ & 5,36 & 26,11 & $3.305,42 \mathrm{~b}$ & $3,89 \mathrm{~b}$ \\
\hline $00+60+30$ & 54,00 & $15,85 \mathrm{~b}$ & 5,53 & 26,23 & $3.589,63 \mathrm{~b}$ & $7,05 \mathrm{~b}$ \\
\hline $45+45+00$ & 56,67 & $17,87 \mathrm{a}$ & 5,45 & 26,80 & $3.364,58 \mathrm{~b}$ & $4,54 \mathrm{~b}$ \\
\hline $00+45+45$ & 62,33 & $19,15 \mathrm{a}$ & 6,12 & 26,17 & $4.088,74 \mathrm{a}$ & $12,59 \mathrm{a}$ \\
\hline $45+00+45$ & 59.00 & $18,82 \mathrm{a}$ & 5,75 & 26,23 & $3.835,54 \mathrm{a}$ & $9,78 \mathrm{a}$ \\
\hline $90+00+00$ & 58,67 & $18,52 \mathrm{a}$ & 5,75 & 26,14 & $3.272,26 \mathrm{~b}$ & $3,52 \mathrm{~b}$ \\
\hline $00+90+00^{(3)}$ & 60,33 & $19,70 \mathrm{a}$ & 5,12 & 26,30 & $3.627,59 \mathrm{~b}$ & $7,47 \mathrm{~b}$ \\
\hline $00+00+90$ & 52,67 & $18,90 \mathrm{a}$ & 5,66 & 26,14 & $3.292,71 \mathrm{~b}$ & $3,75 \mathrm{~b}$ \\
\hline Teste F & $3,60^{\mathrm{ns}}$ & $2,80^{*}$ & $1,84^{\mathrm{ns}}$ & $1,16^{\mathrm{ns}}$ & $2,66 * *$ & $2,66 * *$ \\
\hline Média & 56,25 & 17,99 & 5,60 & 26,37 & $3.519,43$ & 6,83 \\
\hline CV (\%) & 6,41 & 11,3 & 8,66 & 2,94 & 11,26 & 70,25 \\
\hline
\end{tabular}

${ }^{1}$ Médias seguidas pela mesma letra minúscula na coluna não diferem entre si pelo teste de Scott e Knott a 5\% de probabilidade. *, $* *$ significativo a 5 e $1 \%$ de probabilidade, respectivamente e ns - não significativo pelo teste $\mathrm{F} .{ }^{2}$ Quantidade de $\mathrm{N}$ aplicada em cobertura nos estádios fenológicos $\mathrm{V}_{3}$ (formação do primeiro trifólio), $\mathrm{V}_{4}$ (presença da terceira folha trifoliada) e $\mathrm{R}_{5}$ (pré-florescimento), respectivamente. ${ }^{3}$ Dose de $\mathrm{N}$ e estádio fenológico recomendados para o Estado de São Paulo, segundo Ambrosano et al. (1997).

\section{DISCUSSÃO}

Os teores de $\mathrm{N}$ foliar observados foram superiores a faixa de teores considerada adequada para a cultura, 30 a $50 \mathrm{~g} \mathrm{~kg}^{-1}$ (AMBROSANO et. al., 1997), mesmo na ausência de N em cobertura, indicando que a adubação nitrogenada de semeadura (26 kg ha-1 de $\mathrm{N}$ ), a fixação simbiótica, e os processos de mineralização desse nutriente no solo podem ter fornecido $\mathrm{N}$ suficiente para o desenvolvimento das plantas.
Além disso, estudos de Leal et al. (2019) sobre eficiência e responsividade ao $\mathrm{N}$ por cultivares de feijoeiro comum classificaram a cultivar Pérola como eficiente no uso do $\mathrm{N}$ aplicado em cobertura. Outro ponto importante é que é comum a ausência de resposta significativa para o $\mathrm{N}$ foliar em estudos de adubação nitrogenada em feijoeiro comum, já que pode ocorrer efeito de diluição com o aumento de matéria seca proporcionado pela aplicação de N (PEREZ et. al., 2013; 
SORATTO et al., 2013; FLÔRES et al. 2017). Esse valor é superior aos teores médios de $\mathrm{N}$ foliar $(30,7 ; 44,6 ; 45,5$ e 43,9 $\mathrm{g} \mathrm{kg}^{-1}$ ) para a cultivar Pérola verificados por Perez et al. (2013), Sabundjian et al. (2013) e Soratto et al. (2013) e Soratto et al. (2017), respectivamente. No estudo de Soratto et al. (2013), os autores não verificaram diferenças significativas em função da época da época de aplicação de $\mathrm{N}$ (ausência de $\mathrm{N} ; 33$ dias antes da semeadura a lanço; somente na semeadura à lanço; e 23 dias após a emergência em cobertura).
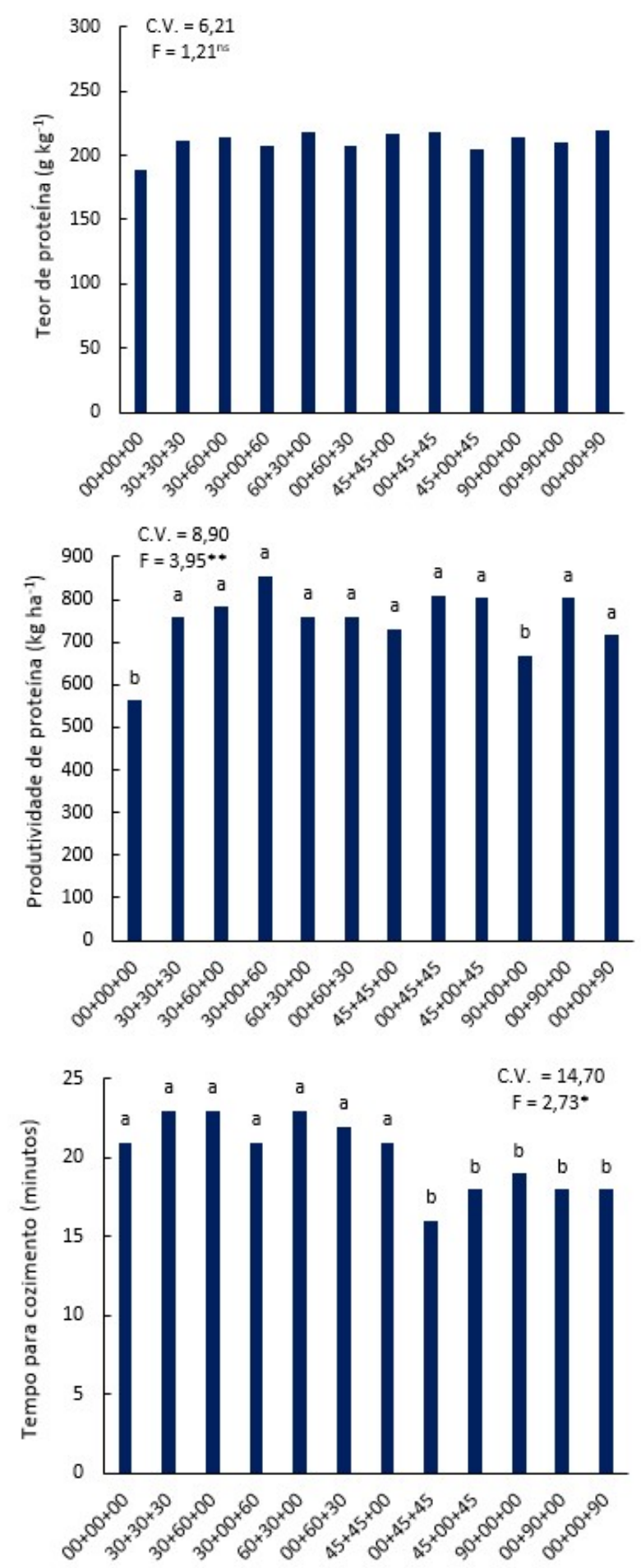

Figura 1. Teor de proteína bruta, produtividade de proteína bruta e tempo para cozimento dos grãos em função do fornecimento da adubação nitrogenada em cobertura no feijoeiro no sistema de preparo convencional do solo, Guaira-SP, $2008^{(1)}$.
Figure 1. Crude protein content, crude protein yield and time for cooking of grains as a function of the topdressing nitrogen supply combinations in conventional soil tillage system, Guaira-SP, $2008^{(1)}$.

Em relação aos componentes de produção, somente o número de vagens foi incrementado com a aplicação de $\mathrm{N}$. Esses resultados estão relacionados ao fato do $\mathrm{N}$ aumentar os níveis de fotossíntese líquida, possibilitando maior número de ramificações e exportação desse nutriente para as estruturas reprodutivas como vagens e grãos (Crusciol et al., 2007; Soratto et al., 2013). No entanto, a ausência de diferenças significativas entre os FN para o número de grãos por vagem pode ter ocorrido devido essa variável apresentar elevada herdabilidade genética, com pouca influência do ambiente (Nascente et al., 2017b). Esses resultados corroboram com Crusciol et al. (2007), Soratto et al. (2013), Flôres et al. (2017) e Leal et al. (2019) que também não constataram incrementos no número de grãos por vagem com o fornecimento de $\mathrm{N}$.

As maiores produtividades de grãos obtidas pelos $\mathrm{FN}$ $30+00+60,00+45+45$ e $45+00+45$ estão associadas aos maiores índices de eficiência agronômica verificados para esses tratamentos, indicando maior aproveitamento do fertilizante nitrogenado aplicado em cobertura. Esses resultados evidenciam a ocorrência de maior eficiência agronômica devido a duas aplicações de $\mathrm{N}$ em cobertura, das quais a segunda foi realizada no estádio de pré-florescimento $\left(\mathrm{R}_{5}\right)$, coincidindo com o período de maior exigência da cultura. Destaca-se também que os tratamentos com a dose única de 90 $\mathrm{kg} \mathrm{ha}^{-1}$ de $\mathrm{N}$ sugerida pelas recomendações (AMBROSANO et al., 1997) apresentou menor produtividade, não diferindo da ausência de $\mathrm{N}$ em cobertura. Esses FN $(30+00+60,00+45+45$ e $45+00+45)$ promoveram acréscimos na produtividade de grãos e eficiência agronômica de 34,38 e $29 \%$ e 13,5 e $9 \%$ em relação à ausência e à aplicação de dose única no estádio $\mathrm{V}_{4}$, respectivamente. Dessa forma, adaptações nas recomendações de adubação nitrogenada devem ser feitas mesmo para o sistema de preparo convencional de solo, adequando-se aos sistemas agrícolas mais modernos. Nesse experimento, os valores de produtividades de grãos foram elevados (acima de $3.000 \mathrm{~kg} \mathrm{ha}^{-1}$ ), o que pode estar relacionado ao teor de matéria orgânica na camada $0-20 \mathrm{~cm}$ no solo $\left(36 \mathrm{~g} \mathrm{~kg}^{-1}\right)$ e adequada distribuição de água (Soratto et al., 2013) proporcionada pelo sistema de irrigação com pivô central que reduzem as perdas e aumentam o fornecimento desse nutriente.

Em relação às características nutricionais e tecnológicas, 0 teor de proteína nos grãos de feijão não foi alterado significativamente pelos $\mathrm{FN}$, o que corrobora com os resultados de Flôres et al. (2017) que não verificaram efeito do parcelamento de $\mathrm{N}$ em cobertura para o feijoeiro. Porém, as menores produtividades de proteína constatadas para os tratamentos sem aplicação de $\mathrm{N}$ e com a dose única de $90 \mathrm{~kg}$ $\mathrm{ha}^{-1}$ em $\mathrm{V}_{3}$ estão relacionadas ao fato de que a ausência ou a aplicação antecipada de $\mathrm{N}$ pode resultar em menor disponibilidade desse nutriente no solo no período de maior exportação para os grãos, acarretando em menor produtividade de grãos. Isso possivelmente decorrente do efeito da salinização do solo e redução da simbiose. Por outro lado, aplicações mais tardias (a partir de $\mathrm{V}_{4}$ ) incrementa o teor proteico nos grãos (GOMES JÚNIOR et al., 2005). Ressaltase que esses foram os tratamentos que não tiveram nenhuma parte do $\mathrm{N}$ aplicado em $\mathrm{V}_{4}$ ou $\mathrm{R}_{5}$. Dessa forma, é importante priorizar estratégias de manejo da adubação que proporcionem 
maior valor agregado proteico aos grãos, principalmente porque o elevado teor de proteínas dos grãos de feijão é um dos fatores que contribuem para o elevado consumo deste alimento na dieta básica dos brasileiros. $\mathrm{O}$ valor médio do teor de proteína obtido nesse experimento foi próximo dos verificados por Silva et al. (2011) para a cultivar Pérola (210 e $\left.220 \mathrm{~g} \mathrm{~kg}^{-1}\right)$.

Para o tempo para cozimento, verificou-se que todos os tratamentos tiveram seus grãos cozidos entre 16 a 23 minutos. No entanto, a aplicação de $\mathrm{N}$ em cobertura afetou positivamente essa característica tecnológica, principalmente para os tratamentos $00+45+45,45+00+45,90+00+00$, $00+90+00,00+00+90$ (16 a 19 minutos), enquadrando os grãos como de suscetibilidade média (16 a 20 minutos) de acordo com a escala de resistência ao cozimento de Proctor; Watts (1987). Os demais FN proporcionaram tempos de cozimentos dos grãos de feijão entre 21 e 23 minutos, que os classificam como de resistência normal segundo a mesma escala. Esses valores são inferiores ao tempo médio de 26 minutos para cozimento de grãos de feijão do cultivar Pérola verificados por Farinelli; Lemos (2010a), com o uso da dose de $90 \mathrm{~kg} \mathrm{ha}^{-1}$ de $\mathrm{N}$ em cobertura, durante a safra das águas. Os baixos tempos para cozimento obtidos no presente experimento podem ser explicados pelo fato de o feijoeiro ter sido colhido em condições de inverno seco. Menores tempos de cozimentos no feijão de outono-inverno são associados a menor ocorrência de precipitação durante a maturidade fisiológica e à colheita. Chuvas na maturidade fisiológica e na colheita podem aumentar o tempo para cozimento, uma vez que interferem na qualidade fisiológica dos grãos, na integridade do tegumento e na absorção de água, como relatado por Farinelli; Lemos (2010b).

Os resultados obtidos nesse experimento demonstram que, além de promover acréscimos na produtividade de grãos e na eficiência agronômica, o FN em diferentes estádios fenológicos do feijoeiro pode ser uma alternativa viável para melhorar as características nutricionais e tecnológicas do grão, principalmente em relação à produtividade de proteína bruta $\mathrm{e}$ no tempo para cozimento. Tal fato pode ser ressaltado na utilização dos parcelamentos $00+45+45$ e $45+00+45$ que proporcionaram resultados positivos para as características agronômicas (produtividades de grãos e eficiência agronômica) e também para as características nutricionais e tecnológicas (produtividade de proteína bruta e tempo para cozimento).

\section{CONCLUSÕES}

Os fornecimentos de N 30+00+60, 00+45+45 e 45+00+45 incrementam a produtividade de grãos e a eficiência agronômica em relação à ausência de $\mathrm{N}$ e à aplicação de dose única no estádio fenológico $\mathrm{V}_{4}$.

Os fornecimentos de $\mathrm{N} 00+45+45,45+00+45,90+00+00$, $00+90+00$ e $00+00+90$ proporcionam as maiores produtividades de proteína bruta e o menor tempo para cozimento.

\section{REFERÊNCIAS}

AMARAL, C. B.; PINTO, C. C.; FLÔRES, J. A.; MINGOTTE, F. L. C.; LEMOS, L. B.; FORNASIERI FILHO, D. Produtividade e qualidade do feijoeiro cultivado sobre palhadas de gramíneas e adubado com nitrogênio em plantio direto. Pesquisa Agropecuária
Brasileira, Viçosa, v. 51, n. 9, p. 1602-1609, 2016. DOI: https://dx.doi.org/10.1590/s0100-204x2016000900060

AMBROSANO, E. J.; WUTKE, E. B.; BULISANI, E. A.; CANTARELLA, H. Feijão. In: RAIJ, B. van; CANTARELLA, H.; QUAGGIO, J. A.; FURLANI, A. M. C. (Ed.). Recomendação de adubação e calagem para o Estado de São Paulo. 2.ed. Campinas: Instituto Agronômico, 1997. p. 194-195. (Boletim Técnico, 100).

AOAC_ASSOCIATION OF OFFICIAL ANALYTICAL CHEMISTS. Official methods of analysis. 16.ed. Washington: AOAC, 1995. $200 \mathrm{p}$.

CERETTA, C. A.; BASSO, C. J.; FLECHA, A. M. T.; PAVINATO, P. S.; VIEIRA, F. C. B.; MAI, M. E. M. Manejo da adubação nitrogenada na sucessão aveia preta/milho, no sistema plantio direto. Revista Brasileira de Ciência do Solo, Viçosa, v. 26, n. 1, p. 163-171, 2002.

CRUSCIOL, C. A. C.; SORATTO, R. P.; SILVA, L. M. da; LEMOS, L. B. Fontes e doses de nitrogênio para o feijoeiro em sucessão a gramíneas no sistema plantio direto. Revista Brasileira de Ciência do Solo, Viçosa, v. 31, n. 6, p. 1545-1552, 2007. DOI: http://dx.doi.org/10.1590/S0100-06832007000600031

EMBRAPA_EMPRESA BRASILEIRA DE PESQUISA AGROPEECUÁRIA. Sistema brasileiro de classificação de solos. 3. ed. Brasília: Embrapa, 2013. 353 p.

FAGERIA, N. K.; STONE, L. F.; SANTOS, A. B.; CARVALHO, M. C. S. Nutrição mineral do feijoeiro. 1. ed. Brasília: Embrapa, 2015. 394 p.

FARINELLI, R.; LEMOS, L. B. Produtividade, eficiência agronômica, características nutricionais e tecnológicas do feijão adubado com nitrogênio em plantio direto e convencional. Bragantia, Campinas, v. 69 , n. 1, p. $165-$ 172, 2010a. DOI: http://dx.doi.org/10.1590/S000687052010000100021

FARINELLI, R.; LEMOS, L. B. Qualidade nutricional e tecnológica de genótipos de feijão cultivados em diferentes safras agrícolas. Bragantia, Campinas, v. 69, n. 3, p. 759764, 2010b. DOI: http://dx.doi.org/10.1590/S000687052010000300030

FIGUEIREDO, M. A.; OLIVEIRA, D. P.; SOARES, B. L.; MORAIS A. R.; MOREIRA, F. M. S.; ANDRADE, M. J. B. Nitrogen and molybdenum fertilization and inoculation of common bean with Rhizobium spp. in two oxisols. Acta Scientiarum: Agronomy, v. 38, n. 1, p. 85-92, 2016. DOI: http://dx.doi.org/10.4025/actasciagron.v38i1.26661

FLÔRES, J. A.; AMARAL, C. A.; PINTO, C. C.; MingotTE, F. L. C.; LEMOS, L. B. Agronomic and qualitative traits of common bean as a function of the straw and nitrogen fertilization. Pesquisa Agropecuária Tropical, Goiânia, v. 47, n. 2, p. 195-201, 2017. DOI: http://dx.doi.org/10.1590/1983-40632016v4743979

GOMES JUNIOR, F. G.; LIMA, E. R.; LEAL, A. J. F.; MATOS, F. A.; SÁ, M. E.; HAGA, K. I. Teor de proteína em grãos de feijão em diferentes épocas e doses de cobertura nitrogenada. Acta Scientiarum: Agronomy, Maringá, v. 27, n. 3, p. 455-459, 2005. DOI: http://dx.doi.org/10.4025/actasciagron.v27i3.1409

KANEKO, F. H.; ARF, O.; GITTI, D. de C.; ARF, M. V.; FERREIRA, J. P.; BUZETTI, S. Mecanismos de abertura de sulcos, inoculação e adubação nitrogenada em feijoeiro em sistema plantio direto. Bragantia, Campinas, v. 69, n. $\begin{array}{llll}1, \quad \text { p. } & 125-133, & 2010 . & \text { DOI: }\end{array}$ 
LEAL, F. T.; FILLA, V. A.; BETTIOL, J. V. T.; SANDRINI, F. O. T.; MingotTE, F. L. C.; LEMOS, L. B. Use efficiency and responsivity to nitrogen of common bean cultivars. Ciência e Agrotecnologia, Lavras, v. 43, p. 112, 2019. DOI: http://dx.doi.org/10.1590/14137054201943004919

MINGOTTE, F. L. C.; GUARNIERI, C. C. O.; FARINELLI, R.; LEMOS, L. B. Desempenho produtivo e qualidade póscolheita de genótipos de feijão do grupo comercial carioca cultivados na época de inverno-primavera. Bioscience Journal, Uberlândia, v. 29, n. 5, p. 1101-1110, 2013.

NASCENTE, A. S.; KLUTHCOUSKI, J.; CRUSCIOL, C. A. C.; COBUCCI, T.; OLIVEIRA, P. de. Adubação de cultivares de feijoeiro comum em várzeas tropicais. Pesquisa Agropecuária Tropical, Goiânia, v.42, n.4, p.407-415, 2012. DOI: http://dx.doi.org/10.1590/S198340632012000400003

NASCENTE, A. S.; CARVALHO, M. C. S.; MELO, L. C.; ROSA, P. H. Nitrogen management effects on soil mineral nitrogen, plant nutrition and yield of super early cycle common bean genotypes. Acta Scientiarum. Agronomy, Maringá, v. 39, n. 3, p. 369-378, 2017a. DOI: http://dx.doi.org/10.4025/actasciagron.v39i3.32781

NASCENTE, A. S.; STONE, L. F.; MELO, L. C. Common bean grain yield as affected by sulfur fertilization and cultivars. Revista Ceres, Viçosa, v. 64, n. 5, p. 548-552, 2017b. DOI: http://dx.doi.org/10.1590/0034737X201764050013

PEREZ, A. A. G.; SORATTO, R. P.; MANZATTO, N. P.; SOUZA, E. F. C. Extração e exportação de nutrientes pelo feijoeiro adubado com nitrogênio, em diferentes tempos de implantação do sistema plantio direto. Revista Brasileira de Ciência do Solo, Viçosa, v. 37, n. 5, p. 1276-1287, 2013. DOI: http://dx.doi.org/10.1590/S010006832013000500017

PROCTOR, J. R.; WATTS, B. M. Development of a modified Mattson Bean Cooker procedure based on sensory panel cookability evaluation. Canadian Institute of Food Science and Technology Journal, Toronto, v. 20, n. 1, p.9-14, 1987. DOI: https://dx.doi.org/10.1016/S03155463(87)70662-2

SABUNDJIAN, M. T.; ARF, O.; KANEKO, F. H.; FERREIRA, J. P. Adubação nitrogenada em feijoeiro em sucessão a cultivo solteiro e consorciado de milho e Urochloa ruziziensis. Pesquisa Agropecuária Tropical, Goiânia, v. 43, n. 3, p. 292-299, 2013. DOI: http://dx.doi.org/10.1590/S1983-40632013000300007

SILVA, T. R. B.; LEMOS, L. B.; CRUSCIOL, C. A C. Produtividade e características tecnológicas de cultivares de feijão em resposta à calagem superficial em plantio direto. Bragantia, Campinas, v. 70, n. 1, p. 196-205, 2011. DOI: http://dx.doi.org/10.1590/S000687052011000100026

SOARES, B. L.; FERREIRA, P. A. A.; RUFINI, M.; MARTINS, F. A. D.; OLIVEIRA, D. P.; REIS, R. P.; ANDRADE, M. J. B.; MOREIRA, F. M. S. Agronomic and economic efficiency of common-bean inoculation with rhizobia and mineral nitrogen fertilization. Revista Brasileira de Ciência do Solo, Viçosa, v. 40, p. 1-13, 2016.

DOI: http://dx.doi.org/10.1590/18069657rbcs20150235

SORATTO, R. P.; CATUCHI, T. A.; SOUZA, E. F. C.; GARCIA, J. L. N. Plant density and nitrogen fertilization on common bean nutrition and yield. Revista Caatinga, Mossoró, v. 30, n. 3, p. 670-678, 2017. DOI: http://dx.doi.org/10.1590/1983-21252017v30n315rc

SORATTO, R. P.; FERNANDES, A. M.; PILON, C.; CRUSCIOL, C. A. C.; BORGHI, E. Épocas de aplicação de nitrogênio em feijoeiro cultivado após milho solteiro ou consorciado com braquiária. Pesquisa Agropecuária Brasileira, Brasília, v. 48, n.10, p. 1351-1359, 2013. DOI: http://dx.doi.org/10.1590/S0100-204X2013001000006 